\title{
Numerical Simulation of Heat Transfer and Steel Shell Growth in a Curved Slab Mold
}

\author{
Saul GARCIA-HERNANDEZ, 1)* José de Jesús BARRETO ${ }^{1)}$ Rodolfo D. MORALES ${ }^{2)}$ and \\ Hugo ARCOS-GUTIERREZ ${ }^{3)}$
}

1) Instituto Tecnológico de Morelia, Metallurgy Graduate Center, Av. Tecnológico No.1500 C.P.58120, Morelia, Mich., México. $\quad 2$ 2) Instituto Politecnico Nacional -ESIQIE, Department of Metallurgy and Materials Engineering, Apdo. Postal 75-874, México City, México. $\quad 3$ 3) Graduate student, Instituto Tecnológico de Morelia, Metallurgy Graduate Center, Av. Tecnológico No.1500 C.P.58120, Morelia, Mich., México.

(Received on September 15, 2012; accepted on January 25, 2013)

\begin{abstract}
The main aims of the present research is the study of steel flow under temperature gradient to understand the convective effects on the flow patterns inside the mold and its effects on the shell growth kinetics under more realistic conditions. In order to achieve this, a non-isothermal mathematical model is developed based on the Navier-Stokes equations together with the k- $\varepsilon$ turbulence model, the volume of fluid model to solve the multiphase system air-slag-steel and a solidification model. Comparing isothermal and non-isothermal results, it is observed that the buoyancy forces are large enough to modify radically the lower recirculation flows inducing shorter and upwards streams; however, the upper recirculation flows do not show strong changes. Shell growth does not necessarily follow a steady parabolic growth and it is more dependent on the washing effects of convective steel streams. Therefore, shell thickness reports heterogeneous and irregular magnitudes through the four faces of the slab. In addition, mold curvature provides uneven shell growth in the inner side of the slab while in the outer side the shell thickness observes a more regular growth. Shell thickness is irregular and discontinuous all around the upper periphery of the slab; therefore, this region is very sensitive to cracking. Finally, the numerical results for liquid steel solidification are compared to published results of shell growth showing a very good qualitative agreement.
\end{abstract}

KEY WORDS: shell growth kinetic; curved slab mold; multiphase system; heat transfer; mathematical simulation.

\section{Introduction}

Steel shell growth is fundamental to provide mechanical strength to the solidifying slab in the continuous casting mold and to maintain machine integrity and productivity of the casting shop. Stable shell growth depends on steel grade, temperature superheat, casting speed, flux chemistry and physical properties of mold powder. For instance, NajeraBastida et al. ${ }^{1,2)}$ analyzed the thinning effects of a wrong application of an acid powder to cast a peritectic steel in a billet mold using numerical simulations and a mass transfer multiphase model to predict a strand breakout. The mathematical simulations predicted a steady shell growth using a basic mold powder for this steel grade. Therefore, the role of shell growth kinetics and casting stability are strongly influenced by the combination of a mold powder and the submerged entry nozzle design for some given casting parameters such as casting speed, temperature superheat and steel grade. Another factor influencing the fluid flow and consequently, affecting evenness of shell thickness is the mold curvature which was simulated by Garcia-Hernandez

* Corresponding author: E-mail: iq_sagahz@hotmail.com

DOI: http://dx.doi.org/10.2355/isijinternational.53.809 et al., ${ }^{3)}$ where the importance of this parameter was analyzed. On the other hand, given the enormous importance of mold fluxes, researchers around the world have made great efforts to characterize the thermo-physical properties of mold fluxes, such Kawamoto et al. ${ }^{4)}$ who identify critical heat fluxes for generating longitudinal cracks of 1.0 and 2.4 $\mathrm{MW} / \mathrm{m}^{2}$ for peritectic and low carbon (0.05 mass\%) steels, respectively. Cho et al. ${ }^{5-7)}$ claims that slow cooling is required for casting surface-cracking sensitive medium carbon-peritectic steels, using basic mold powders with high crystallization rates.

There have been various attempts to predict shell thickness evolution along the slab mold length; however, most of those predictions deliver regular-parabolic shell growths without considering the washing effects of heat transfer convection by the steel flow. ${ }^{8-15)}$ It is evident that the extreme shell thinning effects lead to strand breakouts and here is the importance of understanding shell growth mechanisms to cast peritectic steels; in addition, this steel is known for presenting more longitudinal cracks.

Under these considerations, the main objectives of the present research work are: a) the simulation of steel flow under temperature gradients which will allow the comparison of the results with flow patterns generated under isother- 
mal conditions such as those conditions applied for water modeling of steel flow in molds. ${ }^{16-18)}$ This approach will be useful to evaluate the reliability and validity of water model experiments representing a contribution to the efforts in the field of continuous casting of steel. b) To study the shell growth kinetics numerically under more realistic conditions considering flux infiltration. The liquid peritectic steel solidification results will be validated against published results of shell growth in order to obtain a qualitative comparison between both sources of data, and a final evaluation will be related with the validity and its usefulness to study the solidification process in the continuous casting of steel.

\section{Mathematical Model}

\subsection{Fluid and Turbulence Model}

The fluid model is based on the solution of the NavierStokes equations for incompressible viscous flow. The focus of the present study is the heat transfer and solidification effects inside the slab mold. Therefore, the turbulence model was kept as simple as possible without affecting the overall solution. The $\mathrm{k}-\varepsilon$ model has been proved to give acceptable results in previous works ${ }^{19,20)}$ and it is used here to save computing time. The fundamentals of Navier-Stokes and the $\mathrm{k}-\varepsilon$ equations of this model can be found in different sources. ${ }^{21-23)}$

\subsection{Multiphase Model}

The Volume of Fluid (VOF) model ${ }^{24,25)}$ was employed to solve the multiphase system air-steel-slag. This scheme performs the calculation of the interface between the phases ( $p$ and $q$ ) present at each cell, based on their fraction as shown below;

$$
\begin{aligned}
& \rho_{\text {mix }}=\alpha_{\rho} \rho_{\rho}+\left(1-\alpha_{q}\right) \rho_{\rho} \\
& \mu_{\text {mix }}=\alpha_{\rho} \mu_{\rho}+\left(1-\alpha_{q}\right) \mu_{\rho}
\end{aligned}
$$

A unique continuity equation for the transient system is derived depending on the number of phases. Mass exchange between phases can be modelled introducing an additional source term $\left(S_{\alpha_{q}}\right)$.

$$
\frac{\partial}{\partial t}\left(\alpha_{q} \rho_{q}\right)+\nabla \cdot\left(\alpha_{q} \rho_{q} \vec{v}\right)=S_{\alpha_{q}}+\sum_{p=1}^{n}\left(\dot{m}_{p q}-\dot{m}_{q p}\right) \ldots
$$

The VOF model solves a single set of momentum transfer equations when two or more phases coexist in the cell.

$$
\begin{aligned}
\frac{\partial}{\partial t}\left(\rho_{\text {mix }} \vec{v}\right)+\nabla \cdot\left(\rho_{\text {mix }} \vec{v} \vec{v}\right) & =-\nabla p+\nabla\left[\mu_{\text {mix }}(\nabla \vec{v}+\nabla \vec{u})\right] \\
& +\rho_{\text {mix }} \beta \Delta T g-S_{s}+S_{\sigma}
\end{aligned}
$$

The tracking of the interface is accomplished by an implicit method, which solves the face fluxes $(\dot{m})$ in each grid cell through Eq. (5).

$$
\begin{aligned}
& \frac{\alpha_{q}^{n+1} \rho_{q}^{n+1}-\alpha_{q}^{n} \rho_{q}^{n}}{\partial t} V+\sum_{f}\left(\rho_{q}^{n+1} U_{f}^{n+1} \alpha_{q . f}^{n+1}\right) \\
& =\left[S_{\alpha q}+\sum_{p=1}^{n}\left(\dot{m}_{p q}-\dot{m}_{q p}\right)\right] V
\end{aligned}
$$

\subsection{Heat Transfer and Solidification Models}

\subsubsection{Heat Transfer}

The steel, slag and air share the energy equation which is written as follows.

$$
\frac{\partial}{\partial t}(\rho E)+\nabla \cdot(\vec{v}(\rho E+p))=\nabla \cdot(k \nabla T)
$$

For the top mold, and bottom mold for face the next boundary condition is considered.

$$
-k(T) \frac{\partial T}{\partial y}=0
$$

For the hot face of the mold the next boundary condition is considered: The heat flux to the mold walls was considered unidirectional as a function only of the mold length (Y coordinate) and it was constant in all the walls. This function was obtained from instrumented molds as reported by Yamauchi et al. $^{26)}$ which includes the air and steel zones. This heat flux profile was adjusted by curve fitting techniques according to:

Narrow mold walls

$$
\begin{aligned}
-k(T) \frac{\partial T}{\partial y} & =-86414027.18 y^{4}+103868121.34 y^{3} \\
& -37597994.70 y^{2}+5027814.05 y \\
& +725571.18
\end{aligned}
$$

Wide mold walls

$$
\begin{aligned}
-k(T) \frac{\partial T}{\partial y} & =-1 *\left(-120979638.05 y^{4}+135028557.74 y^{3}\right. \\
& \left.-48877393.11 y^{2}+6536158.26 y+943242.53\right)
\end{aligned}
$$

\subsubsection{Solidification Model}

The solidification profile is calculated for the slag or the steel phase $(p, q)$ based on an enthalpy method where the liquid fraction is calculated by: ${ }^{26}$

$$
f_{l}=\frac{T_{q}-T_{q, \text { solidus }}}{T_{q, \text { liquidus }}-T_{q, \text { solidus }}}
$$

The heat transfer is modified by the latent heat evolution of the steel and slag during their solidification considering only one joint mushy zone. The temperature variation as a function of the effective thermal conductivity of the phase in question is calculated by: ${ }^{24)}$

$$
\frac{\partial}{\partial t}\left(\rho_{q} E\right)+\nabla \cdot\left(\rho_{q} \vec{v} E\right)=\nabla \cdot(k \nabla T)
$$

An enthalpy-porosity technique is used to include the velocity sink resulting from the solidification. This term reduces the melt velocity depending on the solidification fraction at each cell as show in Eq. (12). ${ }^{24)}$

$$
S_{s}=\frac{\left(1-f_{l}\right)^{2}}{\left(0.001+f_{l}^{2}\right)} A_{m u s h}\left(\vec{v}-v_{c}\right)
$$

Equations, (1) through (12), together with the melting and solidification points of the mold flux were used to simulate flux infiltration and related melting-solidification phenomena in the mold-strand gap. 


\section{Model Considerations}

A numerical model was developed for a slab mold and solved based on the CFD commercial software FLUENT ${ }^{\circledR}$. Figure 1 shows the dimensions of physical domains that includes the geometries of the nozzle and the mold. Figure 2 shows the computational mesh for the mold and the nozzle, which has a total of 2500000 cells in a structured mesh in the metal/flux and flux/mold interfaces, and a hybrid mesh in regions close to the SEN. The mesh was refined in the slag zone in order to have a better interfaces definition. The inlet velocity is calculated to maintain the desired casting speed at the outlet. A pressure inlet condition is applied at the mold top $(\mathrm{P}=101325 \mathrm{~Pa}, \mathrm{~T}=300 \mathrm{~K})$ to model the effects of a system open to the atmosphere. The slag is supplied on this boundary by calculating the mass of slag per time unit and it was adjusted during the simulation in order to maintain the slag thickness. To calculate mold flux consumption there are many empirical correlations based on analysis of plant data such as those determined by Kwon et al., ${ }^{27)}$ Nakajima et $a l .{ }^{28)}$ and Wolf ${ }^{29)}$ for slabs and blooms, but when the oscillation characteristic are not available the most recommendable for slabs is the modified Wolf relation $^{29)}$ written as follows:

$$
Q=\frac{0.55}{\mu^{0.5}{ }_{\text {flux }} v_{c}}
$$
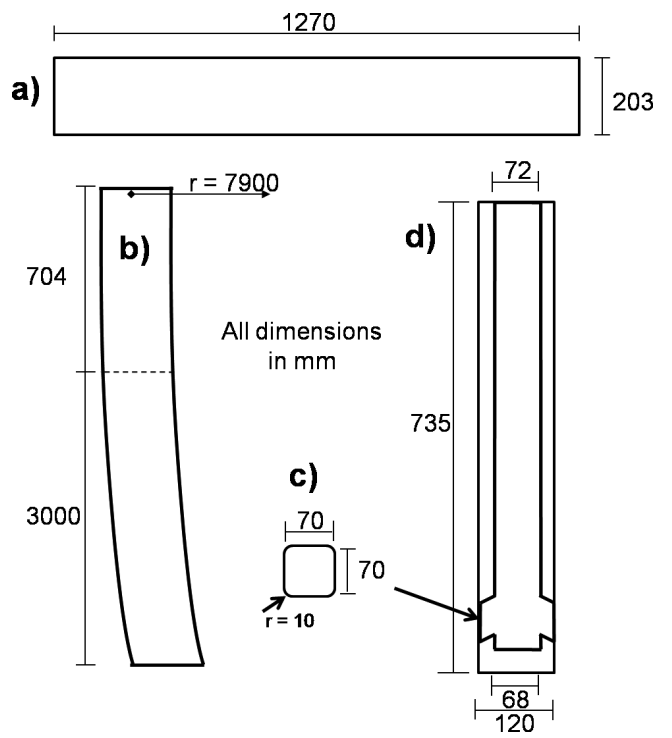

Fig. 1. Mold and SEN geometry, a) Top view, b) Lateral view, c) Port view and d) frontal SEN view.

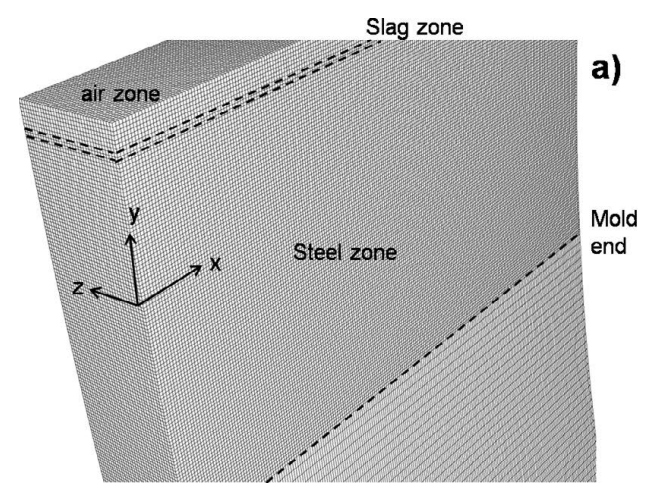

b)

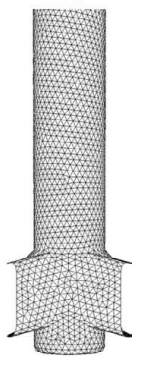

Fig. 2. Computational grid, a) Mold and b) SEN.
To calculate mold flux viscosity Iida model was employed due to its easy application and accuracy. ${ }^{30)}$ Steel chemistry and its physical properties as well as the casting conditions employed on the simulations are presented in the Table 1. The steel under study has a peritectic solidification mechanism. Thereby, the appropriate mold flux to cast this steel must have a chemical basicity higher than one such as that shown in Table 2. This steel characteristic was selected because is the steel which presents more longitudinal cracks due to inefficient control of the solidification.

The implicit computational segregated-iterative method was employed in this work. This method solves the momentum equations using current values of pressure and face mass fluxes in order to update the velocity field which is checked for converging with a modified version of the continuity equation involving the pressure field in a Poisson's

Table 1. Casting parameters and Thermo-physical properties.

\begin{tabular}{|c|c|}
\hline Casting parameter & Value \\
\hline Casting speed $(\mathrm{m} / \mathrm{min})^{* *}$ & 0.9 \\
\hline Casting temperature $\left({ }^{\circ} \mathrm{C}\right)^{* *}$ & 1560 \\
\hline Nozzle immersion $(\mathrm{m}) * *$ & 0.2 \\
\hline Air zone (Free board) $(\mathrm{m})^{* *}$ & 0.05 \\
\hline \multicolumn{2}{|l|}{ Steel properties* } \\
\hline $\mathrm{Cp}(\mathrm{J} / \mathrm{kg}-\mathrm{K})$ & 720 \\
\hline Thermal conductivity $(\mathrm{W} / \mathrm{m} \mathrm{K})$ & 32.7 \\
\hline Density $\left(\mathrm{kg} / \mathrm{m}^{3}\right)$ & $8586-0.8567 \mathrm{~T}(\mathrm{~K})$ \\
\hline Viscosity (Pa s) & 0.0064 \\
\hline Melting heat $(\mathrm{J} / \mathrm{kg})$ & 250000 \\
\hline Liquidus temperature $\left({ }^{\circ} \mathrm{C}\right)$ & 1523.44 \\
\hline Solidus temperature $\left({ }^{\circ} \mathrm{C}\right)$ & 1498.28 \\
\hline Superheat $\left({ }^{\circ} \mathrm{C}\right)$ & 36.5 \\
\hline \multicolumn{2}{|l|}{ Air properties } \\
\hline Thermal conductivity $(\mathrm{W} / \mathrm{m} \mathrm{K})$ & 0.06 \\
\hline Density $\left(\mathrm{kg} / \mathrm{m}^{3}\right)$ & 1.225 \\
\hline Viscosity (Pa s) & $1.789 \times 10^{-5}$ \\
\hline \multicolumn{2}{|c|}{ Steel composition** } \\
\hline \multicolumn{2}{|c|}{$\begin{array}{l}* \text { Steel chemistry in mass \%: } \mathrm{C}=0.07, \mathrm{Mn}=0.94, \mathrm{Si}=0.17 \\
\mathrm{~V}=0.03, \mathrm{Cd}=0.046, \mathrm{Ca}=0.03, \mathrm{Al}=0.03 \text { and } \mathrm{Cu}=0.23\end{array}$} \\
\hline
\end{tabular}

Table 2. Chemistry and physical properties of mold flux*.

\begin{tabular}{lc}
\hline \multicolumn{1}{c}{ Properties } & Value \\
\hline Density $\left(\mathrm{kg} / \mathrm{m}^{3}\right)$ & 2600 \\
Surface tension steel-flux $(\mathrm{N} / \mathrm{m})$ & 1.3 \\
$\mathrm{Cp}(\mathrm{J} / \mathrm{kg} \mathrm{K})$ & 1200 \\
Viscosity $($ Iida model $)(\mathrm{Pa} \mathrm{s})$ & 0.09 \\
Thermal conductivity $(\mathrm{W} / \mathrm{m} \mathrm{K})$ & 1.1 \\
Liquidus temperature $\left({ }^{\circ} \mathrm{C}\right)$ & 1159.85 \\
Solidus Temperature $\left({ }^{\circ} \mathrm{C}\right)$ & 1139.85 \\
\hline Flux chemistry in mass $\%: \mathrm{CaO}=36.35, \mathrm{Al}_{2} \mathrm{O}_{3}=7.35, \mathrm{SiO}_{2}=$ \\
30.26, $\mathrm{Fe}_{2} \mathrm{O}_{3}=0.43, \mathrm{MgO}=1.28, \mathrm{Na}_{2} \mathrm{O}=4.33$, and $\mathrm{C}=5.47$. \\
* Data provided by plant for $\mathrm{specific} \mathrm{conditions.}$
\end{tabular}


type equation. The energy and turbulence equations are later solved using the pressure-velocity fields obtained in the previous step. The non-linear momentum-energy equations were linearized using the implicit approach in combination with the VOF method to define sharp interfaces. The interfaces simulated here are; shell/liquid slag, liquid slag/solid slag, solid slag/mold hot face and metal/slag. It is worthy to mention that recently Ramirez-Lopez et al ${ }^{13-15)}$ proposed a detailed mechanism for the formation oscillation marks considering also the flux infiltration through the gap formed by the shell and the mold using the VOF model. The only heat transfer boundary condition used by those authors was the extraction rate of heat by the cooling mold water, therefore, avoiding the classical heat flux boundary condition. However, computing requirements using this approach are very demanding. ${ }^{13-15)}$ For this reason in the present work, and in order to simplify computations, the effects of mold oscillating motion were not considered here. It is important to point out, that even mold oscillation was not considered, which facilities the flux infiltration, the shell that leaves the mold will pull the superficial flux inducing the flux infiltration. This approximation seems to be reasonable considering that the present work is focused on shell growth and the effect of fluid flow on it, rather than on superficial slab defects. The discretized finite volume equations yield a set of linear simultaneous equations for all cells which is solved through a Gauss-Seidel method. Discretization of the governing equations was performed using the first upwind scheme as first approach. The body weighted scheme was used for pressure interpolation; this scheme computes the cell-face pressure by assuming that the normal gradient of the difference between pressure and body forces is constant. The algorithm used for pressure-velocity coupling was that known as SIMPLEC. ${ }^{31)}$ All cases were solved under unsteady conditions. The time step was maintained around 0.01 seconds. Converging criterion was established when the sum of residuals for all flow and energy variables are smaller than $10^{-4}$. The system of equations is initially solved under isothermal conditions until a stable flow pattern is reached after approximately 300 seconds of computational real time. Subsequently, the heat transfer in the system is solved until a steady temperature field is obtained approximately after 100 seconds of calculation. Finally, the solidification model was activated to calculate the shell growth along the metallurgical height.

\section{Results and Discussion}

\subsection{Fluid Flow under Isothermal and Non-Isothermal Conditions}

Firstly, it is important to analyze the effect of the convection flow on the dynamics of the mold. Figures 3(a) and 3(b) show the average velocity fields of steel under isothermal and non-isothermal conditions, respectively. In both figures the discharging jets impact the narrow faces forming the typical double roll flow pattern; the upper roll flow carries steel toward the SEN, following trajectories below the free surface. Comparing upper roll flows in both cases, it can be seen that the differences are small. The eyes of recirculation under isothermal conditions are slightly rounded and melt velocities in the mold corners are also little higher than those esti- mated under non-isothermal conditions. Out of those small differences both fluid flow patterns are quite similar. However, the lower roll flows are completely different; under isothermal conditions there is a large recirculating flow with an ascending stream that impacts the bottom of the SEN. These recirculations are considerable asymmetric due to the oscillating nature of the jets and the great amount of fluid that interacts with them. Under non-isothermal conditions, temperature gradients decrease the length of the recirculating flow and steel ascends toward the jet position leaving a stream of small velocities impacting the SEN bottom; in addition, these smaller recirculations show a better symmetry since the lower roll flows do not interact as much as in the isothermal case. Figures 4(a)-4(d) show closer views of velocity fields of the upper roll flow in one half of the mold width under isothermal (Figs. 4(a)-4(b)) and non-isothermal conditions (Figs. 4(c) and 4(d)). Comparing Figs. 4(a) and 4(c), it can be observed that temperature gradients induce a thinning effect of the discharging jet since buoyancy forces rise up part of the steel stream in the jet. Close to the ports, Figs. 4(b) and 4(d), both flows are very similar with considerable backflows directed towards the upper port edge. To estimate quantitatively the buoyancy forces responsible for the large changes of the lower roll flow under non-isothermal conditions, the inertial force along the jet axis was calculated using the relationship $\rho_{\text {steel }} v^{2} / L_{j}$ where $\mathrm{L}_{\mathrm{j}}$ is the reference length given by the distance from the SEN port until the impinging point of the jet at the narrow face, $v$ is steel veloc-
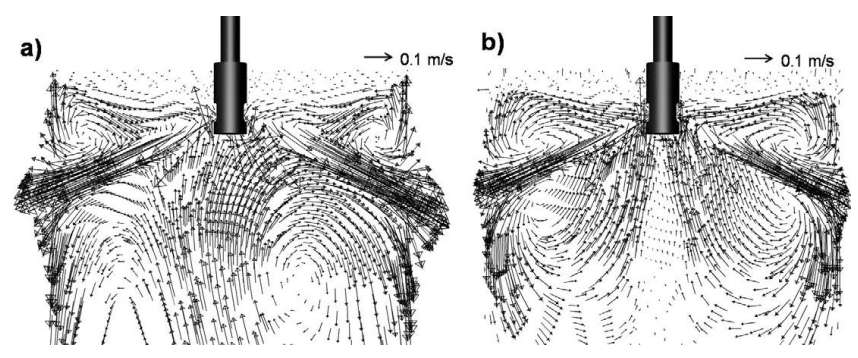

Fig. 3. Velocity Vectors at the central - symmetrical plane. a) Isothermal conditions and b) Non-isothermal conditions.

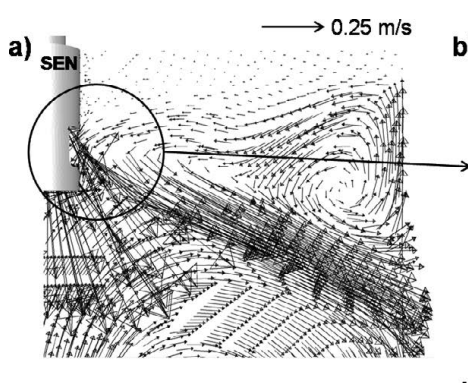

c)
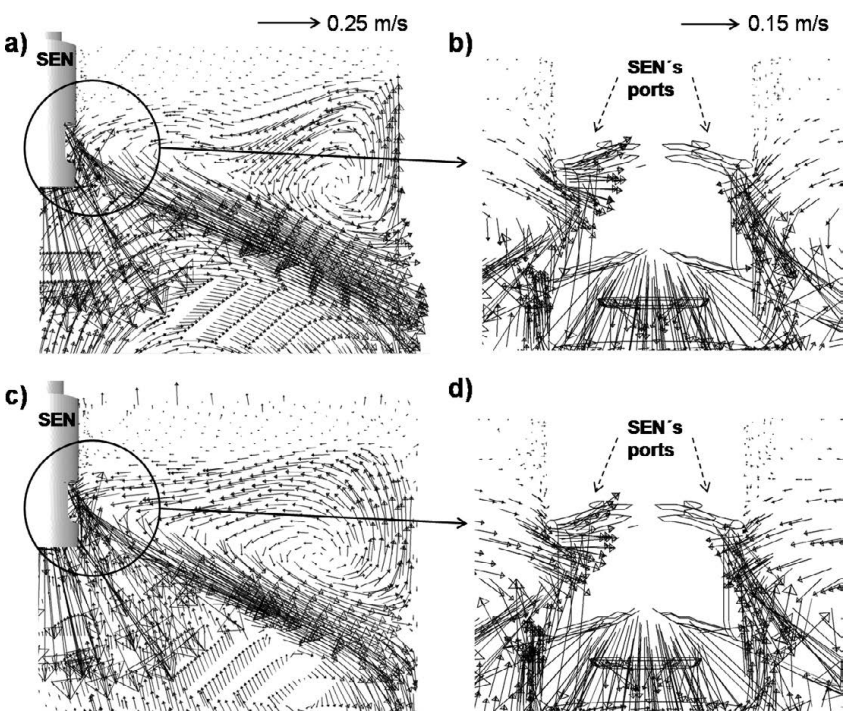

d)

Fig. 4. Velocity Vectors at the central -symmetrical plane with a close up in the SEN ports zone. a) and b) Isothermal conditions, c) and d) non-isothermal conditions. 
ity. This inertial force was also calculated for isothermal conditions when buoyancy forces are nonexistent; therefore the difference between these two calculations provides an estimation of these forces along the jet which are plotted in Fig. 5. As could be expected after $0.1 \mathrm{~m}$ of jet length, the effects of the buoyancy forces become important. Buoyancy forces reach a peak close to a distance of $0.5 \mathrm{~m}$ along the discharging jet and its magnitude represents about $10 \%$ of the inertial forces. This is a small but very significant ratio considering that it is along the axis of the jet where the inertial forces are the largest in the entire flow field. In addition, it can be observed in Fig. 3 that the lower roll flow is affected under thermal gradient conditions because the descending streams along the narrow mold faces are shorter than those under the isothermal flow and produce a smaller flow recirculation which ascends faster towards the SEN tip; these variations can be attributed to the mentioned buoyancy force effect on the jet. As many researches are validated by physical modeling making great emphasis on the meniscus stability, ${ }^{2,16,18)}$ this analysis makes evident the usefulness of isothermal water models to design SEN's since the main concern of this technique is to come out with a steel feeding device that must avoid formations of vortex flows, large amplitude meniscus-standing waves, slag entrapment and general stable flows which deliver fresh steel to the mold corners.

\subsection{Shell Growth}

In order to study the shell growth dynamic, the liquid

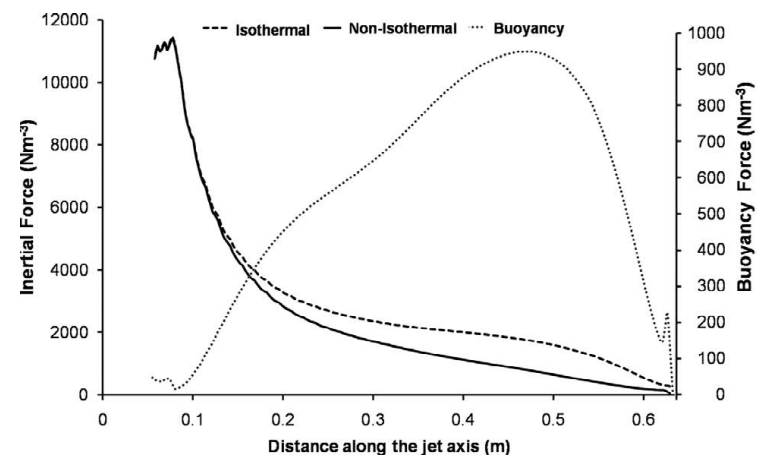

Fig. 5. Inertial to Buoyancy Force Balance at a line along the axis of the right jet.

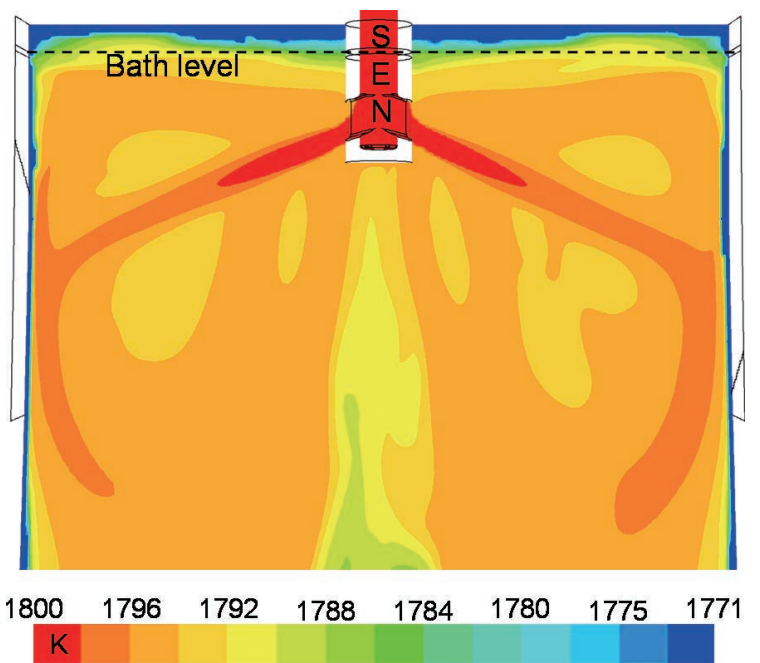

Fig. 6. Temperature contours at the central -symmetrical plane. steel fraction was predicted. This variable ranges from 0 to 1; where 0 represents a total solidification fraction and 1 represents full molten steel. Considering this, for example, a liquid fraction of 0.3 will represent a solidified shell fraction of 0.7 .

The thermal field at the central-symmetrical plane under the casting conditions described here is shown in Fig. 6. It is observed that steel looses the superheat temperature by the high heat flux through the mold walls inducing the largest temperature gradients near them enhancing the shell growth. Step temperatures gradients are observed in regions close to the meniscus. According with these results, it is certain that there are temperature gradients even in the steel bulk. For instance, in regions below the SEN tip and the eyes of the recirculating flows above and below both jets (see Fig. 3(b)), melt velocities are smaller comparing with those regions in the jets inducing moderate temperature gradients. Shell growths, expressed as liquid fraction magnitudes from top views of the mold, are presented in Figs. 7(a)-7(d) at different metallurgical heights. The first plane in Fig. 7(a) was drawn at the meniscus level; it should be noticed that the initial solidification profile is irregular and shows greater growths at regions between nozzle walls and mold wide walls. Moving down to the next plane (Fig. 7(b)),

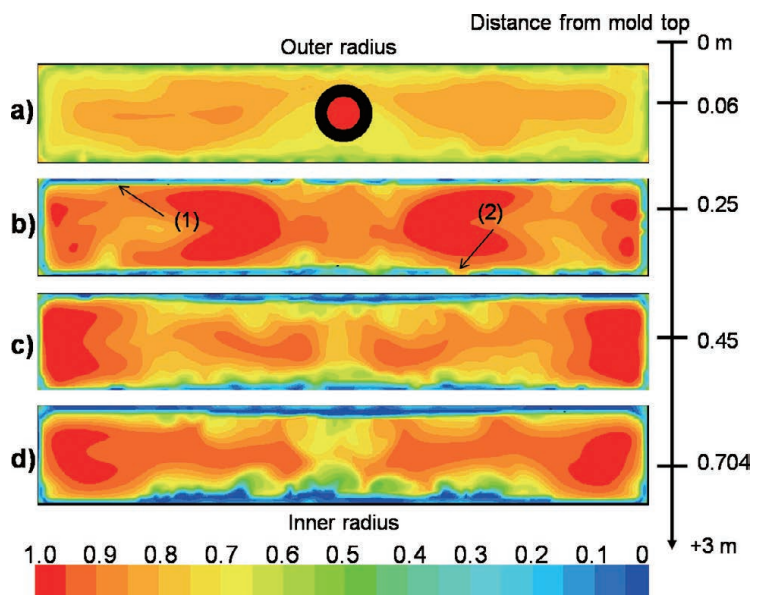

Fig. 7. Liquid steel fraction contours at different metallurgical heights, a) At the meniscus, b) At the SEN bottom, c) At the middle of the mold, and d) At the mold end.

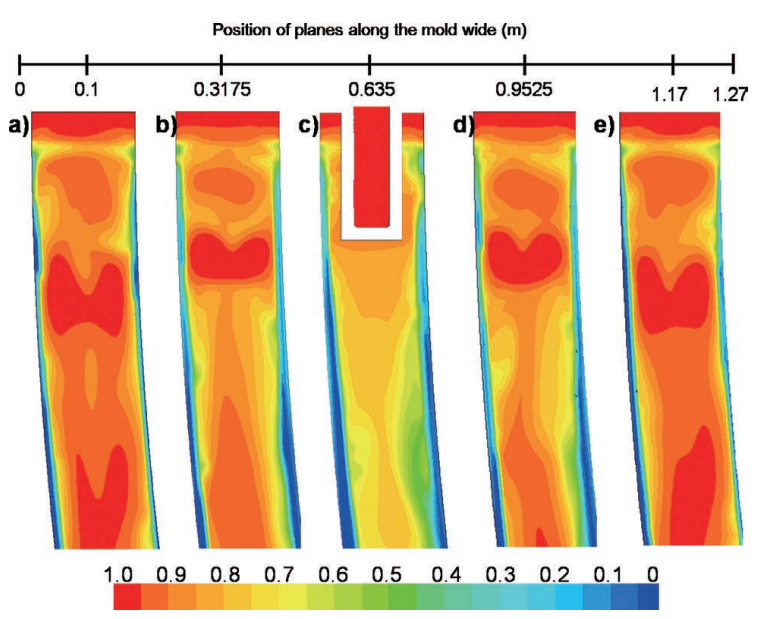

Fig. 8. Liquid steel fraction contours at five parallel planes to the narrow mold walls. 
it can be seen a more defined and uniform shell thickness with some thin regions as is indicated by the arrows (1) and (2), respectively. At the middle of the mold height, Fig. 7(c), the shell thickness decreases in the narrow walls as a consequence of the remelting phenomenon induced by the impinging of the jets on those walls. At the same time, there is an increase of shell thickness at the mid-wide mold face owing to the long residence time of slow movement of steel in these regions. The shell growth at this level is very irregular mainly in the inner mold side. The last plane, at the mold end (Fig. 7(d)), shows the shell thickness at the moment when it leaves the mold. There is a uniform shell thickness in the narrow faces and in the outer side of the mold, but in its inner side the irregular shell growth continues. Figures 8(a)-8(e) show liquid fractions and shell thickness in vertical planes located close to the narrow wall, at the mid position between the narrow mold faces and the SEN and the plane corresponding to the SEN location. As can be observed, shell thickness increases from the narrow mold faces to the central plane. Moreover, along any of those planes the shell does not follow a continuous growth starting from the parabolic pattern expected from heat diffusion principles. The shell suffers of thinning effects due to the wear action induced by the jet impinging and the small differences between both narrow faces is a results of the variations presented by the oscillating jets. The shell is thicker at the central part of the mold since there the melt speeds are smaller whereas in planes closer to the narrow mold faces the effects of the discharging jets dominate.

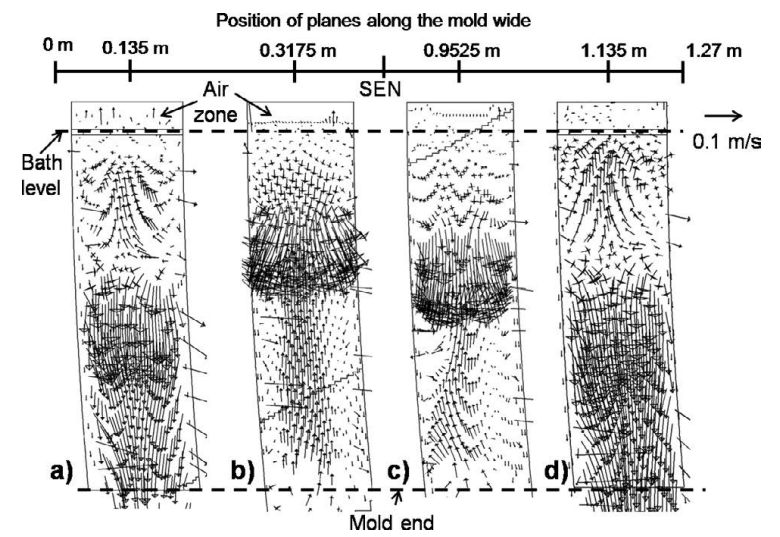

Fig. 9. Velocity vectors at four parallel planes to the narrow mold walls.

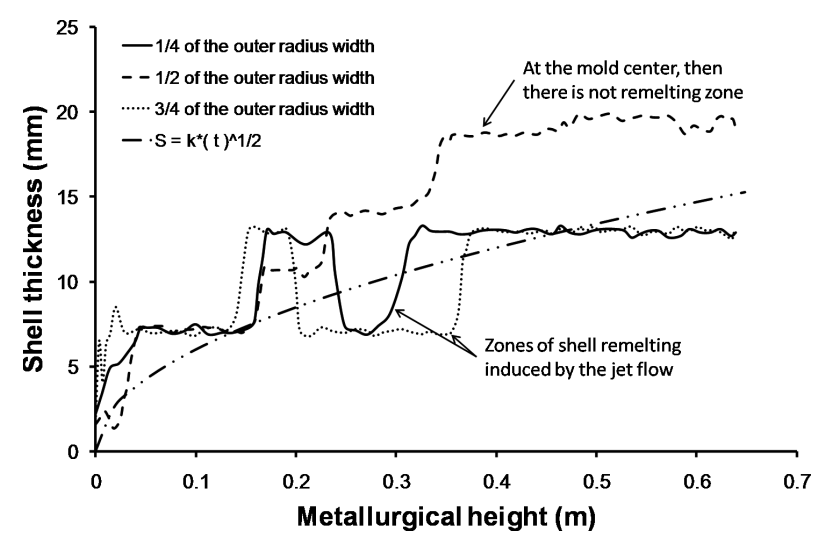

Fig. 10. Predicted shell thickness at the outer mold radius.
Velocity fields in the two lateral planes of Fig. 8 (excluding the central plane) are presented in Fig. 9. In the planes closer to the narrow mold faces, the melt velocities are large forming the upper and lower roll flows. These streams are responsible of the shell thinning effects. In the planes closer to the mold centre, the melt velocity is slower allowing a thicker shell. Shell growth along the metallurgical height for the outer and inner mold sides is shown in Figs. 10 and 11, respectively (at $1 / 4$, at $1 / 2$, and at $3 / 4$ of the mold width). In the outer side, Fig. 10, shell growth follows similar behaviors at the three positions. In this figure a remelting phenomenon about $0.2 \mathrm{~m}$ below the meniscus is observed at $1 / 4$, and at $3 / 4$ of the mold width, this is a consequence of the jet flowing and the heat transfer. However, at the SEN position, below the SEN tip, there is not shell wear and the shell grows considerably thicker than the other two positions. This is the effect of the very slow convection up-stream impacting the SEN tip (Fig. 3), which does not have enough momentum to wash the shell. At the last $0.25 \mathrm{~m}$ of the mold length, the shell thicknesses at these positions are partially recovered to reach about $13 \mathrm{~mm}$ at the mold end giving an average of 16 $\mathrm{mm}$. The shell in the mold inner side (Fig. 11) is subjected to smaller thinning effects by convective melt streams because the jets have more tendency towards the outer radius as can be observed in Fig. 9. Shell thicknesses at the three referenced positions, at the mold end, yield an average value of $19 \mathrm{~mm}$. Both figures show some growth steps seemingly instantaneous (around $5 \mathrm{~mm}$ ), these steps are actually more soft as can be seen in Fig. 8, but it was difficult to follow this soft trend in such a small distance.

A more adequate value of the liquid fraction to observe the shell growth should be 0.2 since this represents a steel shell solidification fraction of 0.8 ; however with this value the shell variations are not so clear; then, an average value of 0.5 was chosen in order to have a better $3 \mathrm{D}$ view of the shell. Figures 12(a)-12(c) show 3D views of the shell at 0.5 of solid fraction, it must be clarified that the empty regions in the upper side of the shell do not mean lack of solidification; those regions indicate that the solid fraction is smaller than 0.5 . Besides, those regions which seem to have a deeper topography indicate that solid fraction is higher than 0.5 . Those differences explain the apparent excessive roughness of the slab surface. It is important to observe in Figs. 12(a) and 12(b) the existence of different shell thicknesses at the meniscus level. Generally speaking, those discontinu-

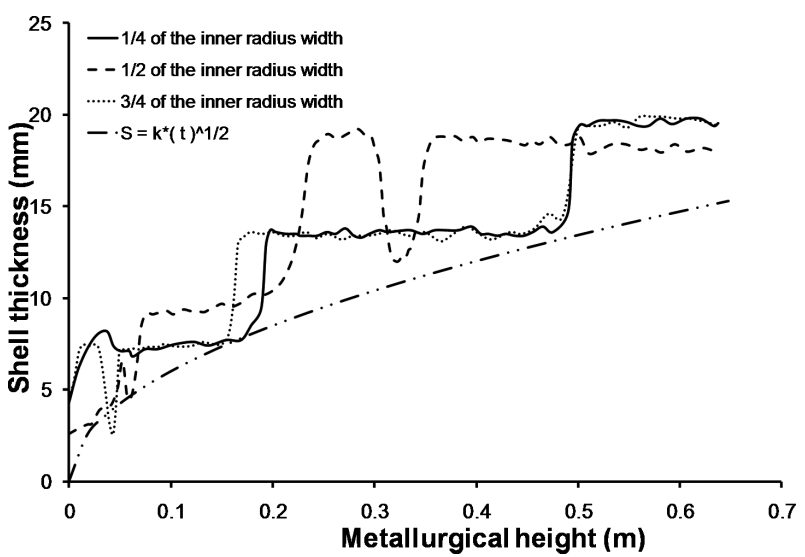

Fig. 11. Predicted shell thickness at the inner mold radius. 
ities of solid fraction are independent from the positions of the cooling channels and apparently more dependent from the local energy transportation through convective mechanisms. From these results, it is evident that plots of shell thickness against metallurgical height, like those presented in Figs. 10 and 11, will yield irregular shapes far away from those reported in previous studies. ${ }^{32,33)}$ The steep variations of solid fraction around the mold at the meniscus level and the irregular shell growth could explain the generation of longitudinal cracks because of the residual stresses; ${ }^{34,35}$ ) these will be easily nucleated through any variation of heat transfer that may lead to temperature gradients and thermal stresses, which will produce weak shell strength. Shell thickness variations depend on the position of the reference line, through which the shell thickness is predicted using the results of this model, from the meniscus to the mold end. In other words, it is hardly to think that shell thickness will evolve following the perfect parabolic law according to the well known relationship: ${ }^{36)}=K \sqrt{t}$. This relation corresponds to the energy transfer by diffusion mechanisms, but does not respond to the local fluid flow effects inducing the shell thinning phenomena. Such a relation can be conceived only as a rough approximation to a complex-multiphase system. Indeed, the curves plotted on Figs. 10 and 11 were predicted using an average value for the solidification constant equal
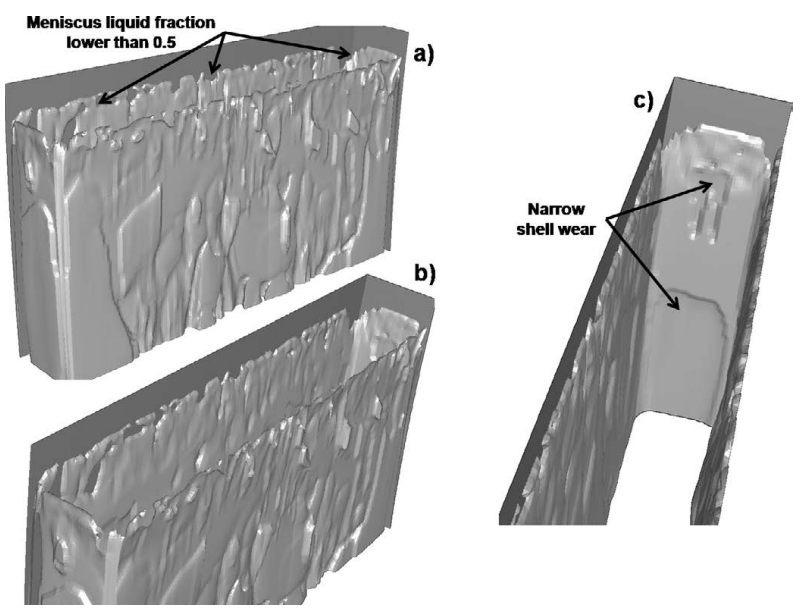

Fig. 12. Solidified shell growth profile for a liquid steel fraction of 0.5 , a) and b) Isometric frontal views, and c) Thinning view of the shell in a narrow wall.

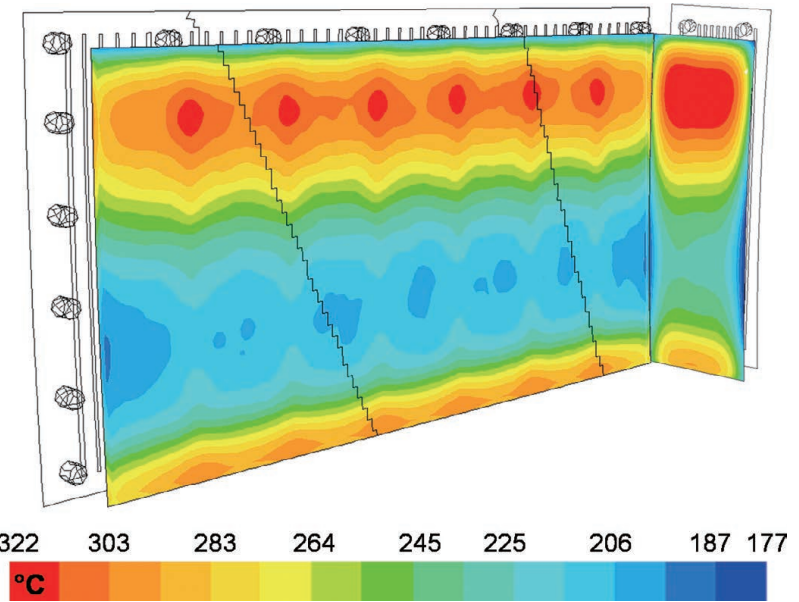

Fig. 13. Temperature contours in the hot mold wide face. to $18 \mathrm{~mm} / \mathrm{min}^{1 / 2}$ for slab molds using casting powders. ${ }^{36)}$ As can be observed in those plots, this simple expression agrees very well with the shell thicknesses simulated at the mold end. It is worthy to mention here that magnitudes of $\mathrm{K}$ for solidification inside the mold are usually smaller than those reported for the spray cooling section where its magnitudes
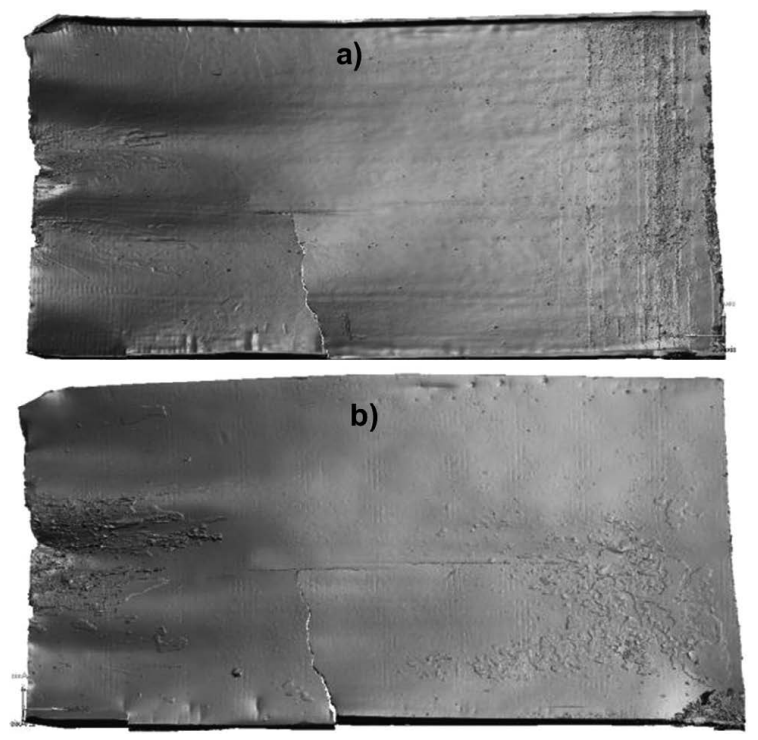

Fig. 14. Aspect of the breakout shells in a thin slab mold reported by Santillana ${ }^{38)}$ a) Inner side and b) Outer side.

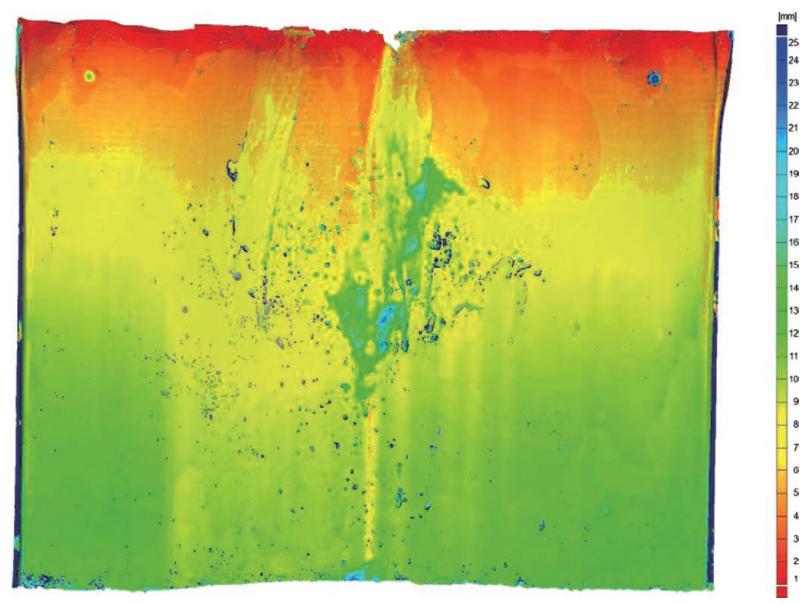

Fig. 15. Shell thickness measured over the entire thin slab wide face reported by Santillana. ${ }^{38}$

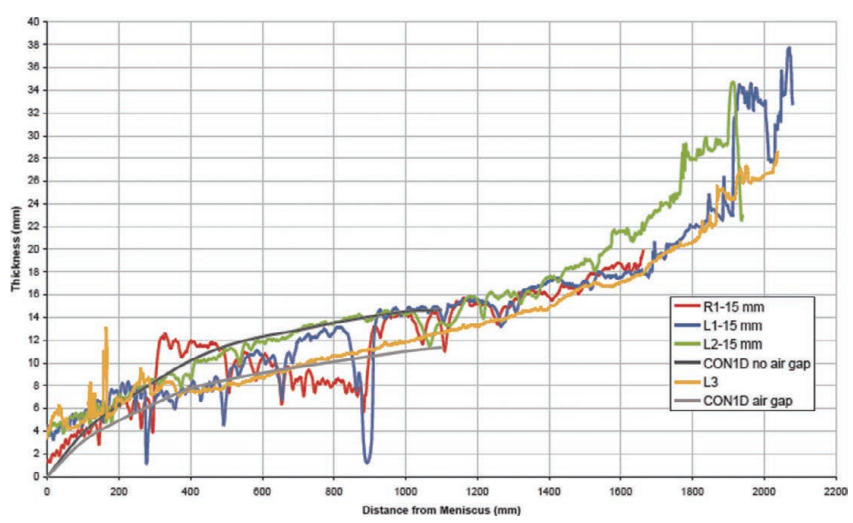

Fig. 16. Predicted and measured Shell thickness reported by Santillana. ${ }^{38}$ 
may go from 22 up to $30 \mathrm{~mm} / \mathrm{min}^{1 / 2}$ for cooling water consumptions from 0 to $1.351 / \mathrm{kg}$ of cast steel. Thereby, $\mathrm{K}$ in the mold is more dependent on casting parameters such as steel superheat, casting speed, steel throughput and physical-chemical properties of the casting powder. In the cooling secondary system, where convection streams are weak and the shell thickness is large the magnitude of $\mathrm{K}$ depends mainly on the amount of water employed.

Figure 13 shows the numerical temperature contours in the hot wide and narrow faces. The results show a longitudinal band of high temperatures located in the first $0.6 \mathrm{~m}$ from meniscus, another thinner hot band in the lowest part of the mold at the region where cooling slots are not present, and zones of coolest temperature at the mold corners because of the two-directional heat transfer through the narrow and wide mold walls; these results agree with thermocouples readings reported previously. ${ }^{37}$

\subsection{Practical Implications}

It is well known that excessive localized shell thinning due to shearing effects on the mushy regions by melt streams may derive into strand breakouts. The present numerical results also indicate that mold curvature provides different shell growth patterns along the mold length. Shell growth during the first $350 \mathrm{~mm}$ below the meniscus is critical, since growth and thinning mechanisms operate one after the other as these simulation reveals. If one of them dominates either the shell thickness will be stabilized or the thinning will be so severe that the shell will not withstand the metallic pressure and the friction forces promoting a strand breakout. Santillana et al. reported a study of a breakout in a thin slab mold. ${ }^{38)}$ The inner and outer aspects of the breakout shells are shown in Figs. 14(a) and 14(b), respectively. These authors used a 3D laser measurement technique in combination with an optical coordinate measuring machine (TRITOP) being able to measure the shell thickness over the entire slab wide face, their results can be observed in Fig. 15. This image makes evident that the breakout shell does not have a constant thickness showing prints of localized shell thinning and localized excessive shell growth just as the present model predicts. The local reduction in shell thickness sometimes reaches magnitudes close to $50 \%$. Figure 16, from the same study, shows the shell growth from the meniscus down the mold length. Although conventional and thin slab molds have radical thermal and flow dynamics characteristics it can be said that there is an agreement with the present model predictions, at least qualitatively, since these measurements indicate the existence of localized shell thinning and localized excessive shell growth regions depending on the chosen line of reference, either along the slab width or the slab length. In Fig. 16 there are predictions of shell growth following the parabolic growth behavior, but the continuous trends of those plots are unable to detect those localized changes of shell thickness. In other words, parabolic approaches based on heat diffusion do not take into account the important effects of fluid flow and cannot detect particular shell changes that may derive into a breakout. According with the presented results, this model shows potential to be applied to any combination of SEN design, flux chemistry and operating conditions of the mold.

\section{Conclusions}

A numerical study of heat, momentum and steel solidification in a slab mold has been performed and the conclusions derived from the corresponding results can be drawn as follows:

(1) By comparing isothermal and non-isothermal flow simulations, it is observed that buoyancy forces are large enough to modify radically the lower recirculating flows and the double roll flow pattern, inducing shorter and upwards streams.

(2) Magnitude of buoyancy forces reaches a peak at approximately $0.5 \mathrm{~m}$ from the mold top along the jet axis. The order of magnitude of the maximum buoyancy force is slightly smaller than $10 \%$ of the maximum inertial force at the port of the SEN.

(3) Shell growth does not necessarily follow a steady parabolic growth and in fact, it is more dependent on the washing effects of convective steel streams carrying sensible heat inside the mold. Therefore, shell thickness reports heterogeneous and irregular magnitudes through the four faces of the slab. Heavy and localized shell thinning may derive into a strand breakout.

(4) Mold curvature provides uneven shell growth in the inner side of the slab while in the outer side the shell thickness observes a more regular growth. Shell thickness at the meniscus level is independent from the positions of the cooling slots in the mold. However, shell thickness is irregular and discontinuous all around the upper periphery of the slab. Therefore, this region is very sensitive for cracking.

(5) The developed multiphase model proves to be useful to analyze complex flows and its effects on shell growth in continuous casting molds.

\section{Acknowledgements}

The authors gratefully acknowledge the National Council of Science and Technology (CONACYT-Mexico) and the institutions IPN, ITM, SNI, and PROMEP for all support given to carry out this work. Casting data provided by Arcelor Mittal Lazaro Cardenas is also acknowledged.

\section{Nomenclature}

$$
\begin{aligned}
\rho & =\text { Density }\left(\mathrm{kg} / \mathrm{m}^{3}\right) \\
\rho_{\text {mix }} & =\text { Density of the mix }\left(\mathrm{kg} / \mathrm{m}^{3}\right) \\
\rho_{p} & =\text { Density of the phase } \mathrm{p}\left(\mathrm{kg} / \mathrm{m}^{3}\right) \\
\alpha_{q} & =\text { Fraction of the phase } \mathrm{q} \\
\alpha_{p} & =\text { Fraction of the phase } \mathrm{p} \\
\mu_{p} & =\text { Viscosity of the phase } \mathrm{p}(\mathrm{Pa} \mathrm{s}) \\
\mu_{f l u x} & =\text { Flux viscosity }(\mathrm{Pa} \mathrm{s}) \\
\mu_{m i x} & =\text { Viscosity of the mix }(\mathrm{Pa} \mathrm{s}) \\
\dot{m}_{p q} & =\text { Mass transfer from phase } \mathrm{q} \text { to phase } \mathrm{p} \\
\dot{m}_{q p}= & \text { Mass transfer from phase } \mathrm{p} \text { to phase } \mathrm{q} \\
S_{\alpha_{q}}= & \text { Source term } \\
\vec{v} & =\text { Overall velocity vector }(\mathrm{m} / \mathrm{s}) \\
n+1= & \text { Index for new (current) time step } \\
n= & \text { Index for previous time step } \\
\alpha_{q, f}= & \text { Face value of the } q^{\text {th }} \text { volume fraction, comput- } \\
& \text { ed from the first or second order upwind }, \\
& \text { QUICK, modified HRIC, or CICSAM scheme } \\
V= & \text { Volume of cell (m } \left.{ }^{3}\right) \\
U_{f}= & \text { Volume flux through the face, based on nor- }
\end{aligned}
$$


mal velocity

$\beta=$ Coefficient of thermal expansion $(1 / \mathrm{K})$

$g=$ Gravitational acceleration $\left(\mathrm{m} / \mathrm{s}^{2}\right)$

$T=$ Temperature $(\mathrm{K})$

$\Delta T=$ Temperature gradient $(\mathrm{K})$

$\nabla \cdot=$ Divergence

$\nabla=$ Gradient

$E=$ Total energy, activation energy $(\mathrm{J})$

$k=$ Thermal conductivity $(\mathrm{W} / \mathrm{m}-\mathrm{K})$

$T_{q, \text { Solidus }}=$ Solidus temperature of the phase $\mathrm{q}(\mathrm{K})$

$T_{q, \text { Liquidus }}=$ Liquidus temperature of the phase $\mathrm{q}(\mathrm{K})$

$A_{\text {mush }}=$ Mushy zone constant

$f_{l}=$ Liquid volume fraction

$v_{c}=$ Casting velocity $(\mathrm{m} / \mathrm{s})$

$Q=$ Mold flux consumption $(\mathrm{kg} / \mathrm{s})$

\section{REFERENCES}

1) A. Najera-Bastida, R. D. Morales, S. Garcia-Hernandez, E. TorresAlonso and A. Espino-Zarate: ISIJ Int., 50 (2010), 830.

2) E. Torres-Alonso, R. D. Morales, S. Garcia-Hernandez, A. NajeraBastida and A. Sandoval-Ramos: Metall. Mater. Trans. B, 39B (2008), 840.

3) S. Garcia-Hernandez, R. D. Morales, E. Torres Alonso and A. Najera Bastida: Steel Res. Int., 80 (2009), 816.

4) M. Kawamoto, Y. Tsukaguchi, N. Nishida, T. Kanazawa and S. Hiraki: ISIJ Int., 37 (1997), 134.

5) J. W. Cho, T. Emi, H. Shibata and M. Suzuki: ISIJ Int., 38 (1998), 834.

6) J. Cho, H. Shibata, T. Emi and M. Suzuki: ISIJ Int, 38 (1998), 268.

7) J. Cho, H. Shibata, T. Emi and M. Suzuki: ISIJ Int., 38 (1998), 440.

8) Y. Meng and B. G. Thomas: Metall. Mater. Trans. B, 34B (2003), 685 .

9) J. A. DiLellio and G. W. Young: Metall. Mater. Trans. B, 26B (1995), 1225

10) R. A. Hardin, K. Liu and C. Beckermann: Proc. Materials Processing in the Computer Age, Metals and Mater. Soc., Warrendale, PA, (2000), 61.

11) B. G. Thomas, R. O. O'Malley, T. Shi. Y. Meng, D. Creech and D. Stone: Proc. Modelling of Casting, Welding and Advanced Solidification Processes, Shaker Verlag, Aachen Germany, (2000), 769.

12) M. Alizadeh, A. J. Jarohmi and O. Abouali: ISIJ Int., 48 (2008), 161.
13) P. Ramirez-Lopez, B. Santillana, K. C. Mills and P. D. Lee: Proc. Roderick Guthrie Honorary Symp. on Process Metallurgy, McGill Metal Processing Centre, Montreal, Canada, (2011), 167.

14) P. Ramirez-Lopez, K. C. Mills and P. D. Lee: ISIJ Int., 50 (2010), 425.

15) P. Ramirez-Lopez, U. Sjostrom, P. D. Lee, T. Jonsson and K. C. Mills: Proc. 7th ECCC, METEC, Düsseldorf, Germany, (2011), Session 8, 1.

16) J. Herbertson, Q. L. He, P. J. Flint and R. B. Mahapatra: Proc. Steelmaking Conf., ISS, Warrendale, PA, (1991), 171.

17) S. Feldbauer and A. Cramb: Proc. 13th PTD Conf., ISS, Warrendale, PA, (1995), 327.

18) E. Torres-Alonso, R. D. Morales, L. Garcia-Demedices, A. NajeraBastida, J. Palafox-Ramos and P. Ramírez-López: ISIJ Int., 47 (2007), 679.

19) A. Ramos-Banderas, R. D. Morales, J. de J. Barreto and G. SolorioDíaz: Steel Res. Int., 77 (2006), 325.

20) G. Solorio-Díaz, R. D. Morales, J. Palafox-Ramos, L. GarciaDemedices and A. Ramos-Banderas: ISIJ Int., 44 (2004), 1024.

21) S. B. Pope: Turbulent Flows, Cambridge University Press, Cambridge, London, New York, (2000), 373.

22) D. C. Wilcox: Turbulence Modeling for CFD, DCW Industries, La Canada, California, (2000), 103.

23) B. E. Launder and D. B. Spalding: Mathematical Models of Turbulence, Academic Press, London, New York, (1972).

24) Fluent Guides, Fluent Inc., Lebanon, NH, USA, (2007).

25) P. Liovic, J. L. Liow and M. Rudman: ISIJ Int., 41 (2001), 225.

26) A. Yamauchi, S. Itoyama, Y. Kishimoto, H. Tozama and K. Sorimachi: ISIJ Int., 10 (2002), 1094.

27) O. D. Kwon, J. Choi, I. R. Lee, J. W. Kim, K. H. Moon and Y. K. Shin: Proc. Steelmaking Conf., ISS, Warrendale, PA, (1991), 561.

28) K. Nakajima, H. Hiraki, T. Kanazawa and T. Murakami: CAMP-ISIJ, 5 (1992), 1221.

29) M. M. Wolf: Trans. Iron Steel Inst. Jpn., 20 (1980), 718

30) T. Iida, H. Sakai, Y. Kita and K. Shigeno: ISIJ Int., 40 (2000), S110.

31) T. J. Chung: Computational Fluid Dynamics, Cambridge University Press, Cambridge, London, New York, (2002), 106.

32) M. Wolf and W. Kurz: Continuous Casting Series-Vol. 9, Iron and Steel Soc., Warrendale, PA, (1997), 115.

33) M. R. Ozgu and B. Kocatulum: Continuous Casting Series-Vol. 9, ISS, Warrendale, PA, (1997), 231.

34) R. Hardin, P. Du and C. Beckermann: Proc. STEELSIM, METEC, Düsseldorf, Germany, (2011), Session 2, 1.

35) J. K. Brimacombe, F. Weinberg, and E. B. Hawbolt: Metall. Trans. $B, \mathbf{1 0 B}$ (1979), 279.

36) K. J Schwerdtfeger: The Making, Shaping and Treating of Steel, Casting Volume, AIST, Warrendale, PA, (2003), 85.

37) A. S. Normaton, P. N. Hewitt, N. S. Hunter, D. Scoones and B. Harris: Ironmaking Steelmaking, 31 (2004), 357.

38) B. Santillana, B. G. Thomas, G. Botman and E. Dekker: Proc. 7th ECCC, METEC, Düsseldorf, Germany, (2011), Session 3, 1. 